\title{
Effect of Levothyroxine Suppression Therapy on Plasma Thrombin Activatable Fibrinolysis Inhibitor Antigen Levels in Benign Thyroid Nodules
}

\author{
Baris Akinci $^{\mathrm{a}}$ Tevfik Demir $^{\mathrm{a}} \quad$ Abdurrahman Comlekci $^{\mathrm{a}}$ Serkan Yener ${ }^{\mathrm{a}}$ \\ Mehmet Ali Ozcan ${ }^{b}$ Oguzhan Karaoglu ${ }^{c}$ Faize Yuksel $^{b}$ Mustafa Secil ${ }^{c}$ \\ Sena Yesil ${ }^{a}$ \\ Divisions of a Endocrinology and Metabolism and ${ }^{\mathrm{b}}$ Hematology, Department of Internal Medicine, and \\ 'Department of Radiology, Dokuz Eylul University, Izmir, Turkey
}

\section{Key Words}

Levothyroxine $\cdot$ Nodular goiter $\cdot$ Fibrinolysis $\cdot$ Plasminogen activator inhibitor-1 1 Thrombin activatable fibrinolysis inhibitor

\section{Abstract \\ Objective: The aim of this prospective study was to investi- gate the effect of LT4 suppression therapy on plasma throm- bin activatable fibrinolysis inhibitor (TAFI) antigen and plas- minogen activator inhibitor-1 (PAI-1) levels in benign thyroid nodules. We also compared hyperthyroid patients and healthy controls. Subjects and Methods: Twenty premeno- pausal women with benign thyroid nodules were given LT4 suppression therapy for 1 year. Plasma TAFI and PAI-1 anti- gen levels were measured at baseline and after LT4 suppres- sion treatment. The endogenous hyperthyroid group was composed of 19 premenopausal females with newly diag- nosed endogenous hyperthyroidism. Eighteen age-matched euthyroid healthy premenopausal women were enrolled as the control group. Results: TAFI antigen levels decreased af- ter LT4 suppression treatment; however, the difference was not statistically significant ( $p=0.057)$. LT4 treatment resulted}

in a nonsignificant increase in PAl-1 levels. Patients with endogenous hyperthyroidism had decreased levels of TAFI antigen and increased levels of PAl- 1 antigen $(p<0.05)$. There was a negative correlation between the $\mathrm{FT}_{4}$ and TAFI antigen levels. Serum TSH was positively correlated with the plasma levels of TAFI antigen. Conclusion: LT4 suppression therapy for benign thyroid nodules did not result in a significant decrease in TAFI antigen levels in premenopausal women, but endogenous hyperthyroidism was associated with significantly decreased levels of TAFI antigen.

Copyright $\odot 2010$ S. Karger AG, Basel

\section{Introduction}

Since thyroid-stimulating hormone (TSH) was proposed as an etiological factor for the development of thyroid nodules [1], levothyroxine (LT4) suppression therapy has been used for the treatment of benign thyroid nodules. Although it is not recommended routinely, evidence suggests that LT4 suppression therapy may result in a decrease of nodule size in cases with borderline low iodine intake [2].

\section{KARGER \\ Fax +4161306 1234 \\ E-Mail karger@karger.ch}

www.karger.com
(C) 2010 S. Karger AG, Basel

1011-7571/11/0201-0023\$38.00/0

Accessible online at:

www.karger.com/mpp
Dr. Baris Akinci

Division of Endocrinology and Metabolism, Department of Internal Medicine University of Dokuz Eylul

TR-35340 Inciralti, Izmir (Turkey)

Tel. +90 232412 3744, Fax +90 232279 2267,E-Mail baris.akinci@ deu.edu.tr 
Thyroid dysfunction has been associated with altered coagulation [3]. The majority of the evidence indicates that endogenous hyperthyroidism causes activation of the coagulation system $[4,5]$. Several studies have demonstrated fibrinolytic system defects in hyperthyroid subjects $[5,6]$. Suppression in serum TSH has been found to be directly associated with elevated plasma fibrinogen levels [4]. Elevated plasma levels of plasminogen activator inhibitor-1 (PAI-1) antigen have been observed in hyperthyroid patients [3]. It is known that LT4 treatment reverses fibrinolytic system abnormalities in hypothyroid subjects $[7,8]$. On the other hand, the administration of levothyroxine in healthy subjects has been found to be associated with increased plasma von Willebrand factor (vWF) levels [9]. A recent study showed that LT4 suppression therapy for thyroid cancer resulted in decreased fibrinolytic activity [10].

Thrombin activatable fibrinolysis inhibitor (TAFI) is a zymogene that inhibits fibrinolysis through removal of C-terminal lysines from partially degraded fibrin [11]. Recently, we showed that TAFI levels were increased in both overt and subclinical hypothyroidism [8]. Levothyroxine replacement for hypothyroidism was effective in reducing the increased levels of TAFI in hypothyroid subjects [8]. In another previous study, we found that TAFI levels were significantly reduced in hyperthyroid subjects when compared to healthy controls [12]. In this prospective study, we aimed to investigate the effect of LT4 suppression therapy (on TAFI and PAI-1 antigen levels) for benign thyroid nodules. Therefore, we measured plasma TAFI and PAI-1 antigen levels in pre-menopausal women with euthyroid nodular goiter before and after LT4 suppression therapy.

\section{Subjects and Methods}

Twenty-two consecutive premenopausal women with euthyroid nodular goiter who were eligible for the study protocol (without any of the exclusion criteria) were enrolled into this prospective follow-up study (LT4 treatment group). Two patients who did not attend the hospital for follow-up visits were excluded; therefore, the data of 20 patients were analyzed. Patients were evaluated by thyroid ultrasound and ultrasound-guided fine-needle aspiration biopsy (FNAB) to rule out thyroid cancer. Patients were excluded if there was any suspicion for malignancy according to the FNAB and/or ultrasound results. We also included healthy subjects and patients with endogenous hyperthyroidism for comparison. Eighteen age-matched euthyroid healthy premenopausal women were included as the control group. Nineteen premenopausal women who had newly diagnosed endogenous hyperthyroidism (6 patients with Graves' disease and 13 patients with tox- ic nodular goiter) were also included as positive controls. Of 19 hyperthyroid patients, 9 had overt and 10 had subclinical hyperthyroidism. Plasma samples in the hyperthyroid group were obtained from age-matched premenopausal women who had enrolled in our previous study [12].

Exclusion criteria were previous history of thyroid surgery, neck irradiation, cardiovascular disease, diabetes, morbid obesity, hypertension, familial hyperlipidemia, chronic kidney or liver disease, coagulation disorders, current pregnancy, history of malignancy or severe systemic disease, previous and current cigarette smokers, and patients taking lipid-lowering drugs, angiotensin-converting enzyme inhibitors, angiotensin-2 receptor blockers, estrogen, oral contraceptives and any other drugs which may influence the coagulation system (acetylsalicylic acid, warfarin, heparin, glycoprotein IIb/IIIa receptor inhibitors, thienopyridines, etc.). The protocol was approved by the Ethics Committee of Dokuz Eylul University, and all patients gave their written informed consent.

In the LT4 treatment group, patients were evaluated at baseline and after LT4 suppression therapy for 1 year. LT4 was initiated at $25 \mu \mathrm{g} /$ day. The LT4 dose was adjusted according to repeated thyroid function tests which were measured at $0,1,3,6$, and 12 months of the LT4 treatment (average daily dose being $0.05-0.15$ $\mathrm{mg}$ ). Treatment with LT4 was considered suppressive when TSH was $<0.4 \mathrm{mIU} / \mathrm{l}$.

Height was recorded to the nearest $0.5 \mathrm{~cm}$ and weight was measured to the nearest $0.1 \mathrm{~kg}$. Measurements were taken with the subject standing upright. BMI was calculated as weight/height ${ }^{2}$.

Fasting blood samples for TAFI and PAI-1 antigen levels were obtained between 8.00 and 9.00 a.m. from the cannulated antecubital vein in tubes containing $3.2 \%$ buffered sodium citrate. Platelet-poor plasma was obtained by centrifugation at 3,000 $\mathrm{g}$ for 15 min at $4^{\circ} \mathrm{C}$ min in a precooled centrifuge (Nuve NF 800R, Ankara, Turkey). The plasma samples were stored at $-80^{\circ} \mathrm{C}$ until use.

Ultrasound was performed to assess thyroid nodule volumes using a high-resolution ultrasound (Philips HDI 5000, Bothell, Wash., USA) with a 7- to $12-\mathrm{mHz}$ linear array transducer. Images were recorded and evaluated by a single radiologist (O.K.) to avoid interobserver variations. The nodule volume was calculated according to the spherical ellipsoid formula: 3.14/6 $\times$ depth $(\mathrm{mm})$ $\times$ width $(\mathrm{mm}) \times$ height $(\mathrm{mm})$.

Free 3,5, ${ }^{\prime}$-triiodothyronine $\left(\mathrm{FT}_{3}\right)$ and free thyroxine $\left(\mathrm{FT}_{4}\right)$ levels were measured using an immunoassay (Immulite 2000, Diagnostic Products Corporation, Los Angeles, Calif., USA). TSH was measured with a chemiluminescence immunometric assay (Immulite 2000 Diagnostic Products Corporation). Triglyceride, total cholesterol and HDL cholesterol levels were measured by Roche/Hitachi D/P Modular System Autoanalyzer (Roche Diagnostics, Basel, Switzerland). LDL cholesterol was calculated by Friedewald's equation method [13].

PAI-1 antigen levels were measured using enzyme-linked immunosorbent assay (ELISA) kits (American Diagnostica, Stamford, Conn., USA). Plasma TAFI antigen levels were also measured by ELISA (Affinity Biologicals, Ancaster, Ont., Canada). Intra- and interassay coefficients of variation were 4.0 and $4.3 \%$ for PAI-1, and 5.8 and $8 \%$ for TAFI, respectively.

Sample size determination for the LT4 suppression treatment group used a significance level of 0.05 for a two-tailed test with $80 \%$ power. The sample size was calculated using Power and Precision software (Biostat, Englewood, N.J., USA). Data were ana- 
Table 1. Baseline characteristics of patients with euthyroid nodular goiter, endogenous hyperthyroid patients and healthy controls

\begin{tabular}{|c|c|c|c|}
\hline & $\begin{array}{l}\text { Euthyroid } \\
\text { nodular } \\
\text { goiter }(\mathrm{n}=20)\end{array}$ & $\begin{array}{l}\text { Hyperthy- } \\
\text { roidism } \\
(\mathrm{n}=19)\end{array}$ & $\begin{array}{l}\text { Healthy } \\
\text { controls } \\
(\mathrm{n}=18)\end{array}$ \\
\hline Age, years & $41.7 \pm 7.53$ & $40.58 \pm 9.55$ & $39.22 \pm 6.89$ \\
\hline Weight, kg & $64.8 \pm 10.11$ & $63 \pm 8.33$ & $64.89 \pm 8.53$ \\
\hline $\mathrm{BMI}, \mathrm{kg} / \mathrm{m}^{2}$ & $24.26 \pm 3.79$ & $23.89 \pm 3.38$ & $24.78 \pm 3.61$ \\
\hline $\mathrm{FT}_{3}, \mathrm{pg} / \mathrm{ml}^{*, \dagger}$ & $3.19 \pm 0.48$ & $5.45 \pm 2.76$ & $2.98 \pm 0.21$ \\
\hline $\mathrm{FT}_{4}, \mathrm{ng} / \mathrm{dl}^{*}+\dagger$ & $1.38 \pm 0.17$ & $2.34 \pm 1.26$ & $1.37 \pm 0.14$ \\
\hline $\mathrm{TSH}, \mathrm{mIU} / \mathrm{l}^{*, \dagger}$ & $1.77 \pm 1.16$ & $0.08 \pm 0.13$ & $1.62 \pm 0.79$ \\
\hline $\begin{array}{l}\text { Total cholesterol, } \\
\mathrm{mg} / \mathrm{dl}\end{array}$ & 105 & 18 & 24.64 \\
\hline $\begin{array}{l}\text { Triglyceride, mg/dl } \\
\text { HDL-cholesterol, }\end{array}$ & $124.1 \pm 64.32$ & 124.95 & 124.33 \\
\hline $\mathrm{mg} / \mathrm{dl}$ & $63.35 \pm 13.47$ & $55.84 \pm 11.52$ & $57.5 \pm 14.5$ \\
\hline $\begin{array}{l}\text { LDL-cholesterol, } \\
\mathrm{mg} / \mathrm{dl}\end{array}$ & 107. & 104 & 10 \\
\hline PAI-1, ng/ml ${ }^{*, \dagger}$ & $37.35 \pm 23.66$ & $89.77 \pm 33.33$ & $33.19 \pm 11.99$ \\
\hline TAFI, ng/ml*, ${ }^{*}$ & $11.79 \pm 5.85$ & $8.8 \pm 2.27$ & $11.42 \pm 3.04$ \\
\hline
\end{tabular}

${ }^{*} \mathrm{p}<0.05$ (calculated $\mathrm{p}$ values are shown in the text), hyperthyroidism vs. healthy controls; ${ }^{\dagger} \mathrm{p}<0.05$, hyperthyroidism vs. euthyroid nodular goiter. $\mathrm{FT}_{3}=$ Free 3,5,3'-triiodothyronine; $\mathrm{FT}_{4}=$ free thyroxine; HDL = high-density lipoprotein; $\mathrm{LDL}=$ low-density lipoprotein; PAI-1 = plasminogen activator inhibitor-1; TSH = thyroid-stimulating hormone; TAFI $=$ thrombin activatable fibrinolysis inhibitor. Conversion factor (CF) for cholesterol levels $(\mathrm{CF} \times \mathrm{C}=\mathrm{SI}): 0.02586$; $\mathrm{CF}$ for triglyceride $(\mathrm{CF} \times \mathrm{C}=\mathrm{SI}): 0.0114$.

lyzed by Statistical Package of Social Science (SPSS) 11.0 for Windows software package (SPSS Inc., Chicago, Ill., USA). Variable distributions were assessed by the Kolmogorov-Smirnov normality test. One-way ANOVA or Kruskal-Wallis tests were used (considering normality test result) to assess whether there was an overall difference between groups. Bonferroni correction was used for multiple comparisons. Paired samples t tests or Wilcoxon signedrank tests were used to assess the differences between pre- and post-treatment variables, in regard to variable distribution. Correlation analyses were conducted by Spearman's test. Data were expressed as mean \pm SD. Statistical significance was accepted at $\mathrm{p}<0.05$.

\section{Results}

Baseline characteristics of patients with euthyroid nodular goiter, endogenous hyperthyroid and healthy control subjects were similar (table 1). There was no significant difference in lipid levels between the groups. Hyperthyroid patients had higher $\mathrm{FT}_{3}$ and $\mathrm{FT}_{4}$ and sup- pressed TSH levels when compared to patients with euthyroid nodular goiter and healthy controls. Hyperthyroid patients had significantly higher PAI-1 levels than healthy controls $(\mathrm{p}<0.001)$ and patients with euthyroid nodular goiter $(\mathrm{p}<0.001)$. TAFI antigen levels were found to be decreased in hyperthyroid patients (hyperthyroidism vs. healthy controls: $\mathrm{p}=0.011$, hyperthyroidism vs. euthyroid nodular goiter: $\mathrm{p}=0.044)$. Overt hyperthyroid patients had significantly lower TAFI antigen levels when compared with subclinical hyperthyroid patients $(7.9 \pm 2.67$ vs. $9.61 \pm 1.55 \mathrm{ng} / \mathrm{ml}, \mathrm{p}=0.034)$. On the other hand, PAI antigen levels were similar $(92.01 \pm 25.88$ vs. $87.75 \pm 40.21 \mathrm{ng} / \mathrm{ml}, \mathrm{p}=0.514)$. Both overt and subclinical hyperthyroid groups had increased PAI-1 antigen levels compared to healthy controls $(92.01 \pm 25.88$ vs. $33.19 \pm 11.99 \mathrm{ng} / \mathrm{ml}, \mathrm{p}<0.001$, and $87.75 \pm 40.21$ vs. $33.19 \pm 11.99 \mathrm{ng} / \mathrm{ml}, \mathrm{p}<0.001$, respectively). TAFI antigen levels were decreased in both overt and subclinical hyperthyroid groups when compared with healthy control group; however, the difference between subclinical hyperthyroid and healthy control groups was not statistically significant $(7.9 \pm 2.67$ vs. $11.42 \pm 3.04 \mathrm{ng} / \mathrm{ml}, \mathrm{p}=$ 0.012 , and $9.61 \pm 1.55$ vs. $11.42 \pm 3.04 \mathrm{ng} / \mathrm{ml}, \mathrm{p}=0.103$, respectively).

LT4 suppression treatment was not associated with any significant change in both the largest nodule diameter and nodule volume (table 2). There was no alteration in lipid levels after LT4 treatment. There was a nonsignificant increase in PAI levels after LT4 treatment (table 3). TAFI antigen levels decreased after LT4 treatment; however, the difference was not statistically significant $(p=0.057)$. Endogenous hyperthyroid patients had higher PAI-1 levels when compared with post-treatment levels of patients in the LT4 treatment group $(\mathrm{p}<0.001)$. Hyperthyroid patients had slightly less TAFI antigen levels compared to post-treatment levels of those in the LT4 treatment group; however, this difference was not statistically significant (table 3 ).

$\mathrm{FT}_{3}$ and $\mathrm{FT}_{4}$ levels were positively correlated with plasma PAI-1 levels $(\mathrm{r}=0.376, \mathrm{p}=0.001, \mathrm{r}=0.461, \mathrm{p}<$ 0.001 , respectively). $\mathrm{FT}_{4}$ levels were negatively correlated with TAFI antigen levels $(r=-0.252, p=0.027)$. Serum TSH was negatively correlated with plasma PAI-1 ( $\mathrm{r}=$ $-0.530, p<0.001)$. There was a positive correlation between serum TSH and TAFI antigen levels $(\mathrm{p}=0.242$, $\mathrm{p}=0.034)$. 
Table 2. Effect of LT4 suppression treatment on nodule size and volume

\begin{tabular}{lccc}
\hline & Before treatment & After treatment & $\mathrm{p}$ value \\
\hline Nodule size, $\mathrm{mm}(\mathrm{n}=73)$ & $6.6 \pm 6.17$ & $6.6 \pm 6.79$ & 0.398 \\
Nodule volume, $\mathrm{mm}^{3}(\mathrm{n}=73)$ & $426.65 \pm 870.81$ & $446.35 \pm 1,281.42$ & 0.601 \\
Dominant nodule size, $\mathrm{mm}(\mathrm{n}=20)$ & $14.79 \pm 7.45$ & $15.19 \pm 8.89$ & 0.394 \\
Dominant nodule volume, $\mathrm{mm}^{3}(\mathrm{n}=20)$ & $1,238.25 \pm 1,388.01$ & $1,425.11 \pm 2,262.14$ & 0.104 \\
\hline
\end{tabular}

Data are expressed as mean $\pm \mathrm{SD}$.

Table 3. Comparison of altered levels of fibrinolytic system proteins 1 year after LT4 suppression treatment with prior treatment levels and endogenous hyperthyroid patients

\begin{tabular}{|c|c|c|c|}
\hline & $\begin{array}{l}\text { Before } \\
\text { treatment }\end{array}$ & $\begin{array}{l}\text { After } \\
\text { treatment }\end{array}$ & $\begin{array}{l}\text { Hyper- } \\
\text { thyroidism }\end{array}$ \\
\hline $\mathrm{FT}_{3}, \mathrm{pg} / \mathrm{ml}^{\dagger, \ddagger}$ & $3.19 \pm 0.48$ & $3.21 \pm 0.65$ & $2.98 \pm 0.21$ \\
\hline $\mathrm{FT}_{4}, \mathrm{ng} / \mathrm{dl}^{*, \dagger}$ & $1.38 \pm 0.17$ & $1.81 \pm 0.36$ & $1.37 \pm 0.14$ \\
\hline $\mathrm{TSH}, \mathrm{mIU} / \mathrm{l}^{*,+ \text {, }}$ & $1.77 \pm 1.16$ & $0.19 \pm 0.15$ & $1.62 \pm 0.79$ \\
\hline $\begin{array}{l}\text { Total cholesterol, } \\
\mathrm{mg} / \mathrm{dl}\end{array}$ & 195.5 & 190. & 187.1 \\
\hline $\begin{array}{l}\text { Triglyceride, mg/dl } \\
\text { HDL-cholesterol, }\end{array}$ & $124.1=$ & $113.8 \pm 71.25$ & $124.33 \pm 57.72$ \\
\hline $\begin{array}{c}\mathrm{mg} / \mathrm{dl} \\
\text { LDL-cholesterol, }\end{array}$ & $63.35 \pm 13.47$ & $63.75 \pm 15.12$ & $57.5 \pm 14.5$ \\
\hline & $107.33 \pm 31.21$ & 103.94 & 104.7 \\
\hline PAI- $1, \mathrm{ng} / \mathrm{ml}^{\dagger}, \ddagger$ & $37.35 \pm 23.66$ & $44.34 \pm 20.01$ & $33.19 \pm 11.99$ \\
\hline TAFI, ng/ml ${ }^{\dagger}$ & $11.79 \pm 5.85$ & $9.53 \pm 2.81$ & $11.42 \pm 3.04$ \\
\hline
\end{tabular}

Data are expressed as mean \pm SD. ${ }^{*} \mathrm{p}<0.05$, before vs. after treatment; ${ }^{\dagger} \mathrm{p}<0.05$, before treatment vs. hyperthyroidism; ${ }^{\ddagger} \mathrm{p}<$ 0.05 , after treatment vs. hyperthyroidism. $\mathrm{FT}_{3}=$ Free 3,5,3'-triiodothyronine; $\mathrm{FT}_{4}=$ free thyroxine; $\mathrm{HDL}=$ high-density lipoprotein; $\mathrm{LDL}=$ low-density lipoprotein; PAI-1 = plasminogen activator inhibitor-1; TSH = thyroid-stimulating hormone; TAFI = thrombin activatable fibrinolysis inhibitor. Conversion factor $(\mathrm{CF})$ for cholesterol levels $(\mathrm{CF} \times \mathrm{C}=\mathrm{SI})$ : 0.02586; CF for triglyceride $(\mathrm{CF} \times \mathrm{C}=\mathrm{SI}): 0.0114$.

\section{Discussion}

In the present study, LT4 suppression treatment was not associated with a significant change in nodule size and volume, but there was a decrease in TAFI antigen levels after LT4 suppression treatment for benign thyroid nodules; however, this difference was not statistically significant $(\mathrm{p}=0.057)$. LT4 suppression treatment resulted in a non-significant increase in PAI-1 antigen levels. In accordance with our previous study [12], TAFI antigen levels were found to be decreased in patients with endogenous hyperthyroidism. Endogenous hyperthyroid patients had significantly increased PAI-1 antigen levels when compared to healthy controls.

Altered levels of fibrinolytic system proteins have been shown to be associated with cardiovascular disorders [14] and elevated PAI-1 antigen levels have been reported to be a predictor for cardiovascular events [15]. Although some studies suggested that elevated TAFI was associated with increased risk for cardiovascular disease [16-19], it is still controversial [20]. Moreover, it has been also proposed that elevated TAFI antigen levels may be protective against coronary events $[21,22]$. In our study, TAFI levels were decreased in patients with hyperthyroidism and there was a negative correlation between FT4 and TAFI levels. However, our results could not address any potential relationship between decreased TAFI levels and cardiovascular disorders in patients with thyroid dysfunction.

It is known that thyroid dysfunction leads to altered plasma levels of fibrinolytic system proteins [3]. Both hypo- and hyperthyroidism have been found to be associated with decreased fibrinolytic activity [5]. In a previous work [8], we showed that hypothyroidism was associated with increased TAFI antigen levels. We observed that LT4 replacement treatment effectively reduced increased TAFI antigen levels in hypothyroidism. In a more recent study, we were able to detect reduced TAFI antigen levels in hyperthyroid patients [12]. In the present study, however, we failed to show any significant decrease in TAFI antigen levels after LT4 suppression treatment for benign thyroid nodules. The decrease in TAFI antigen levels after LT4 suppression treatment was weak when compared to TAFI levels in patients with endogenous hyperthyroidism, probably due to milder thyroid dysfunction in the LT4 suppression treatment group. Horne et al. [10] demonstrated that LT4 suppression therapy for thyroid cancer was associated with decreased fibrinolytic activity and 
enhanced coagulation. It was interesting that LT4 suppression treatment was found to be associated with decreased TAFI but increased PAI-1 antigen levels. A hypothesis for this might be a decrease in plasma antigen levels of TAFI antigen secondary to activated TAFI pathway. Decreased TAFI antigen levels were found to be correlated with activation of coagulation factors in sepsis [23]. Lower plasma TAFI antigen levels in patients with myocardial infarction have been reported, although TAFI activity was significantly elevated and positively correlated with plasma PAI-1 antigen levels and activity, suggesting overactivation of the TAFI pathway [24]. Another hypothesis could be that plasma levels of PAI- 1 and TAFI antigens might be affected by different factors as these two proteins have various roles in the different steps of the coagulation system. Simultaneous measurements of the circulating levels of TAFI and PAI-1 antigens have been performed in a few studies $[25,26]$, in which no significant correlation was found between plasma TAFI and PAI-1 antigen levels in nonobese patients [26]. As observed in our study, despite the fact that PAI-1 and TAFI are both inhibitors of the fibrinolytic system, their circulating levels might be differently affected by various disorders.

Our study clearly had some limitations that include (a) the small number of subjects that might have led to insig- nificant differences between groups, and (b) the lack of evaluation of the TAFI activity. TAFI exists as a proenzyme that is converted to an active form, TAFIa, following proteolytic cleavage by the thrombin/thrombomodulin complex. The TAFI activity is usually determined by first incubating the plasma with a TAFI activation reagent, a specially formulated thrombin/thrombomodulin complex that converts the TAFI to its activated form $[11,27]$. In the current study, circulating TAFI antigen concentrations was measured with ELISA, and, as we included only premenopausal women with no cardiovascular risk factor, our study could not provide any data regarding TAFI antigen levels in males and postmenopausal women. Moreover, our study could not address the possible relationship between TAFI and cardiovascular risk factors.

\section{Conclusion}

Our study showed that suppression therapy for benign thyroid nodules was associated with a nonsignificant decrease in TAFI antigen levels in premenopausal women. Besides, TAFI antigen levels were significantly decreased in patients with endogenous hyperthyroidism.

\section{References}

1 Studer H, Peter HJ, Gerber H: Natural heterogeneity of thyroid cells: the basis for understanding thyroid function and nodular goiter growth. Endocr Rev 1989;10:125-135.

$\checkmark 2$ Cooper DS: Clinical review 66: thyroxine suppression therapy for benign nodular disease. J Clin Endocrinol Metab 1995;80:331-334.

-3 Erem C, Ersoz HO, Karti SS, Ukinc K, Hacihasanoglu A, Deger O, Telatar M: Blood coagulation and fibrinolysis in patients with hyperthyroidism. J Endocrinol Invest 2002; 25:345-350.

-4 Dorr M, Robinson DM, Wallaschofski H, Schwahn C, John U, Felix SB, Volzke H: Low serum thyrotropin is associated with high plasma fibrinogen. J Clin Endocrinol Metab 2006;91:530-534.

5 Hofbauer LC, Heufelder AE: Coagulation disorders in thyroid diseases. Eur J Endocrinol 1997;136:1-7.

6 Marongiu F, Conti M, Mameli G, Murtas ML, Balzano S, Sorano G, Mamusa AM, Martino E: Fibrinogen and fibrinolytic activity in hyperthyroidism before and after antithyroid treatment. J Endocrinol Invest 1988;11:723-725.
Gullu S, Sav H, Kamel N: Effects of levothyroxine treatment on biochemical and hemostasis parameters in patients with hypothyroidism. Eur J Endocrinol 2005;152: 355-361.

-8 Akinci B, Comlekci A, Ali Ozcan M, Demir T, Yener S, Demirkan F, Yuksel F, Yesil S: Elevated thrombin activatable fibrinolysis inhibitor (TAFI) antigen levels in overt and subclinical hypothyroid patients were reduced by levothyroxine replacement. Endocr J 2007;54:45-52.

9 Rogers JS 2nd, Shane SR, Jencks FS: Factor VIII activity and thyroid function. Ann Intern Med 1982;97:713-716.

10 Horne MK 3rd, Singh KK, Rosenfeld KG, Wesley R, Skarulis MC, Merryman PK, Cullinane A, Costello R, Patterson A, Eggerman T, Bernstein DM, Pucino F, Csako G: Is thyroid hormone suppression therapy prothrombotic? J Clin Endocrinol Metab 2004; 89:4469-4473.

11 Bajzar L: Thrombin activatable fibrinolysis inhibitor and an antifibrinolytic pathway. Arterioscler Thromb Vasc Biol 2000;20: 2511-2518.
12 Akinci B, Comlekci A, Yener S, Demir T, Ozcan MA, Bayraktar F, Yesil S: Thrombin activatable fibrinolysis inhibitor antigen levels are inversely correlated with plasminogen activator inhibitor-1 antigen levels in hyperthyroid patients. Endocr J 2007;54: 593-599.

13 Friedewald WT, Levy RI, Fredrickson DS: Estimation of the concentration of low-density lipoprotein cholesterol in plasma, without use of the preparative ultracentrifuge. Clin Chem 1972;18:499-502.

14 Haverkate F: Levels of haemostatic factors, arteriosclerosis and cardiovascular disease. Vascul Pharmacol 2002;39:109-112.

15 Scarabin PY, Aillaud MF, Amouyel P, Evans A, Luc G, Ferrieres J, Arveiler D, JuhanVague I: Associations of fibrinogen, factor VII and PAI-1 with baseline findings among 10,500 male participants in a prospective study of myocardial infarction - the prime study. Prospective epidemiological study of myocardial infarction. Thromb Haemost 1998;80:749-756. 
16 Schroeder V, Chatterjee T, Mehta H, Windecker S, Pham T, Devantay N, Meier B, Kohler HP: Thrombin activatable fibrinolysis inhibitor (TAFI) levels in patients with coronary artery disease investigated by angiography. Thromb Haemost 2002;88:10201025.

17 Silveira A, Schatteman K, Goossens F, Moor E, Scharpe S, Stromqvist M, Hendriks D, Hamsten A: Plasma procarboxypeptidase U in men with symptomatic coronary artery disease. Thromb Haemost 2000;84:364-368.

18 Lau HK, Segev A, Hegele RA, Sparkes JD, Teitel JM, Chisholm RJ, Strauss BH: Thrombin-activatable fibrinolysis inhibitor (TAFI): a novel predictor of angiographic coronary restenosis. Thromb Haemost 2003;90:11871191.

19 Santamaria A, Martinez-Rubio A, Borrell M, Mateo J, Ortin R, Fontcuberta J: Risk of acute coronary artery disease associated with functional thrombin activatable fibrinolysis inhibitor plasma level. Haematologica 2004; 89:880-881.
20 Morange PE, Tregouet DA, Frere C, Luc G, Arveiler D, Ferrieres J, Amouyel P, Evans A, Ducimetiere P, Cambien F, Tiret L, JuhanVague I: TAFI gene haplotypes, TAFI plasma levels and future risk of coronary heart disease: the prime study. J Thromb Haemost 2005;3:1503-1510.

21 Juhan-Vague I, Morange PE, Aubert H, Henry M, Aillaud MF, Alessi MC, Samnegard A, Hawe E, Yudkin J, Margaglione M, Di Minno G, Hamsten A, Humphries SE: Plasma thrombin-activatable fibrinolysis inhibitor antigen concentration and genotype in relation to myocardial infarction in the north and south of Europe. Arterioscler Thromb Vasc Biol 2002;22:867-873.

22 Juhan-Vague I, Morange PE: Very high TAFI antigen levels are associated with a lower risk of hard coronary events: the prime study. J Thromb Haemost 2003;1:2243-2244.

23 Zeerleder S, Schroeder V, Hack CE, Kohler HP, Wuillemin WA: TAFI and PAI-1 levels in human sepsis. Thromb Res 2006;118:205212.

24 Zorio E, Castello R, Falco C, Espana F, Osa A, Almenar L, Aznar J, Estelles A: Thrombin-activatable fibrinolysis inhibitor in young patients with myocardial infarction and its relationship with the fibrinolytic function and the protein $\mathrm{C}$ system. Br J Haematol 2003;122:958-965.
25 Juhan-Vague I, Renucci JF, Grimaux M, Morange $\mathrm{PE}$, Gouvernet J, Gourmelin Y, Alessi MC: Thrombin-activatable fibrinolysis inhibitor antigen levels and cardiovascular risk factors. Arterioscler Thromb Vasc Biol 2000; 20:2156-2161.

-26 Kitagawa N, Yano Y, Gabazza EC, Bruno NE, Araki R, Matsumoto K, Katsuki A, Hori Y, Nakatani K, Taguchi O, Sumida Y, Suzuki K, Adachi Y: Different metabolic correlations of thrombin-activatable fibrinolysis inhibitor and plasminogen activator inhibitor-1 in non-obese type 2 diabetic patients. Diabetes Res Clin Pract 2006;73:150-157.

27 Boffa MB, Koschinsky ML: Curiouser and curiouser: recent advances in measurement of thrombin-activatable fibrinolysis inhibitor (TAFI) and in understanding its molecular genetics, gene regulation, and biological roles. Clin Biochem 2007;40:431-442. 